\title{
Type of semantic elaboration and recall
}

\author{
SHAHIN HASHTROUDI \\ George Washington University, Washington, D.C.
}

\begin{abstract}
Two experiments examined the effects of various semantic-orienting tasks on immediate and delayed recall. In Experiment 1, words modified by their core or cross-situational properties (necessary adjectives) were recalled better than words modified by more peripheral properties (arbitrary adjectives). In addition, the beneficial effects of necessary adjectives seemed to be independent of the amount of cognitive analysis required for processing these adjectives. In Experiment 2, words modified by necessary adjectives were recalled better regardless of whether the adjectives were general or specific. Overall, the results are consistent with the "core meaning" notion and indicate that the quality of semantic elaboration is an important determinant of recall.
\end{abstract}

The effect of semantic processing on memory has been widely investigated via studies employing an incidental-learning paradigm (Craik \& Tulving, 1975; Hyde \& Jenkins, 1969, 1973; Jenkins, 1974). These studies have usually compared semantic and nonsemantic tasks, and theoretical concepts such as depth of processing (Craik \& Lockhart, 1972) have accounted for the marked superiority of semantic processing.

Recently, however, there has been more interest in encoding differences within the semantic domain (Anderson \& Reder, 1979; Baddeley, 1978; Bransford, Franks, Morris, \& Stein, 1979; Craik \& Tulving, 1975). For example, the idea of spread or elaboration of encoding has been proposed to account for retention differences within the semantic realm (Craik \& Tulving, 1975). Elaboration refers to extensiveness of processing or to the number of encoded features; a greater number of encoded features leads to a more elaborate memory trace and hence to better recall. A number of other studies have also emphasized the importance of the amount of semantic processing (Frase \& Kammann, 1974; JohnsonLaird \& Bethell-Fox, 1978; Johnson-Laird, Gibbs, \& de Mowbray, 1978; Klein \& Saltz, 1976). On the other hand, several studies have shown that the quality of semantic elaboration is an important determinant of recall. For example, in a paired-associate paradigm, the quality of semantic elaboration had a marked effect on long-term retention (Hasher \& Johnson, 1975). Like-

Experiment 2 was supported by a grant from the George Washington University Committee on Research. I would like to thank Marcia K. Johnson for her comments on earlier drafts of this paper. I also thank Carol Raye and Roger Schvaneveldt for their helpful suggestions and criticism. The assistance of Jonathon Billing, Lynn Seagren, and Neima Hirsh in testing subjects is gratefully acknowledged. A portion of this paper was presented at the 18th Annual Meeting of the Psychonomic Society, Washington, D.C., November 1977. Requests for reprints should be sent to Shahin Hashtroudi, Department of Psychology, George Washington University, Washington, D.C. 20052. wise, in incidental-learning situations, certain types of elaborators produced better retention than others (Eysenck, 1979; Jacoby, Craik, \& Begg, 1979; Packman \& Battig, 1978; Stein, Morris, \& Bransford, 1978).

Although qualitative differences in semantic processing are implicated by available data, it appears that further progress on the role of semantic processing in retention will depend on developing theoretical ideas about the nature of these qualitative differences. One possible qualitative distinction that can be drawn between semantic tasks, and that seems intuitively im. portant, is the distinction between core and peripheral aspects of meaning (Hasher, Griffin, \& Johnson, 1977; Hasher \& Johnson, 1975; Hashtroudi \& Johnson, 1976). Hasher et al. (1977) defined core properties as those that "are consistently relevant across occurrences of a concept" (p.44). Core semantic properties will, in general, be the least situation-specific or contextuallydetermined interpretation of a word's meaning.

The basic idea that concepts such as words have core semantic properties has been suggested by other investigators as well (Smith, Shoben, \& Rips, 1974), and reflects a general assumption that information may be weighted in importance with respect to particular concepts (Rosch, 1975). Johnson, Hasher, and Hashtroudi (Note 1) also emphasized a continuum along which some features are closer to the core meaning than others. They stated that there must be some normative agreement on the basic meaning of words ("bird," "has wings," "is an animal"), or else we would not be able to communicate. However, they noted that the core-meaning notion should not be confused with the linguistic or logical concept of analytic meaning (Katz, 1964; Putnam, 1962); core features are not a priori definitional features, but they are relatively cross-situational in the life history of an individual. In many cases, defining ("hot flame") or very salient ("canary sing") properties of concepts are included in the core meaning of the concept, because they are important cross-situationally. In these cases, 
obviously there is normative agreement on core aspects of meaning. In general, people share core meanings to the extent that their past histories are similar or to the extent that the communication context depends on a particular interpretation.

According to Hasher et al. (1977), "elaborators" that activate the central core or the most salient aspects of the meaning of a word help retention to a greater degree than those that activate the more peripheral or situation-specific aspects of meaning. In this view, information is assimilated into preexisting knowledge structures or conceptual categories in varying degrees of closeness to the core properties of a concept. The core meaning of a given word is the most likely "entry point" for the memory search. Thus, the more salient aspects of the meaning of a word would be most likely to be thought of, and they would be more effective retrieval cues than the peripheral aspects of meaning.

Hasher and Johnson's (1975) core-meaning notion was formulated in the context of a paired-associate task. The purpose of the present experiments was to explore whether the advantage of core elaborators extends to a free-recall incidental-learning situation in which no explicit cues are provided for the subjects. Free recall may be guided by cues in the retrieval environment that remain invisible to the experimenter (Roediger \& Thorpe, 1978). It is possible that, in the absence of explicit cues, features of the stimulus and features of the context provide the functional retrieval cues.

Core and peripheral properties are defined in terms of necessary and arbitrary adjectives, respectively. Necessary adjectives (e.g., "leafy LETTUCE," "calibrated RULER") are salient or relatively cross-situational properties of items. ${ }^{1}$ Arbitrary adjectives, on the other hand, are sensible but not cross-situational properties of items (e.g., "rotten LETTUCE," "metric RULER"). It was expected that words modified by necessary adjectives would lead to higher recall than would words modified by arbitrary adjectives. In addition, the effectiveness of the two types of adjectives was tested at two retention intervals, immediately and $48 \mathrm{~h}$ later.

A pilot experiment had established normative data for necessary and arbitrary adjectives and had also provided preliminary support for the core-meaning view. In this experiment, different groups of subjects were presented with a list of 36 nouns paired with necessary or arbitrary adjectives. Two different semantic-orienting tasks were used: (1) a production task, and (2) a rating task. The subjects in the production group wrote necessary or arbitrary modifiers for the nouns, and the subjects in the rating group assigned ratings of 1 to 5 to adjectives, depending on whether the adjectives were considered necessary or arbitrary modifiers of the nouns. Half of the subjects were given a surprise free-recall test for the nouns immediately following the orienting task, and the other half were tested after a 48 -h delay.
The rating data supported the experimenter's intuition about the different types of adjectives. Necessary adjectives had significantly lower ratings (mean $=2.32$, $\mathrm{SD}=.42)$ than did arbitrary adjectives (mean $=3.96$, $\mathrm{SD}=.68$ ). Likewise, the recall data provided some support for the core-meaning view. The interaction of type of adjective and retention interval was significant: Necessary adjectives had a marginally significant advantage after a delay interval. The interpretation of this experiment, however, was limited by the fact that the main effect of adjective was not significant. Experiments 1 and 2 were designed to examine closely the beneficial effects of necessary adjectives and to consider various potential explanations for the superiority of these adjectives.

\section{EXPERIMENT 1}

The purpose of this experiment was to investigate the beneficial effects of necessary adjectives in immediate and delayed recall. In addition, this experiment was designed to explore an alternative interpretation for better recall with necessary adjectives. It can be argued that producing or rating necessary adjectives may be more difficult than producing or rating arbitrary adjectives. For example, finding a cross-situational property for "ENVELOPE" (e.g., "paper") may require more cognitive analysis than finding a merely sensible property (e.g., "sealed," "open," "small," "white," etc.). Thus, subjects may consider more information in producing or rating necessary adjectives, and the greater amount of cognitive analysis may lead to better recall of the items modified by these adjectives. The cognitive-analysis view, therefore, suggests that more extensive processing with necessary adjectives should produce more durable traces, whereas the core-meaning approach emphasizes the nature of semantic elaborators regardless of the degree of cognitive analysis. If the advantage of the necessary task is a function of greater cognitive analysis, then increasing the amount of analysis for the arbitrary case or decreasing it for the necessary case should eliminate or reduce the beneficial effect of necessary adjectives. On the other hand, if the superiority of the necessary task is due to the special quality of necessary adjectives, then recall should be higher with these adjectives regardless of the amount of cognitive analysis.

There were three adjectival conditions in this experiment: Nec-Nec, Arb-Arb, and Nec-Arb. The subjects in the Nec-Nec and the Arb-Arb conditions were presented with two necessary adjectives (e.g., "CANDLE, wax, meltable") or two arbitrary adjectives ("CANDLE, flickering, unlit") following the noun. The subjects in the $\mathrm{Nec}-\mathrm{Arb}$ condition saw one necessary and one arbitrary adjective (e.g., "CANDLE, wax, unlit"). All subjects were instructed to choose the more necessary of the two adjectives. It was assumed that choosing between two arbitrary adjectives (Arb-Arb condition) should be 
approximately as difficult as choosing between two necessary adjectives ( $\mathrm{Nec}-\mathrm{Nec}$ condition) and that any differences between these two groups could be attributed to the special quality of the adjectives. Choosing between a necessary and an arbitrary adjective (Nec-Arb condition) should be relatively easy and should not require extensive processing. Thus, comparison of this group with the other two groups should allow an assessment of the contribution of cognitive analysis versus quality of adjectives to better recall with necessary adjectives.

It should be noted that the operational definition of cognitive analysis in this experiment is similar to the definition of "decision difficulty" recently suggested by Jacoby et al. (1979). These investigators assessed the effect of preexperimental associative strength and decision difficulty on retention. Decision difficulty was manipulated by varying the degree of similarity between two words. For example, in their Experiment 3, subjects were given a "focus" word and asked which of the other two words was highly related to this word. At retrieval, the focus words were presented as cues and the subjects were asked to recall the chosen alternative. Jacoby et al. assumed that, for a given word, such as "water," making a decision between two highly associated words (e.g., "thirst" and "lake") would be a more difficult task than making a decision between one high associate and one low associate. The effect of decision difficulty was assessed by holding the associative strength of the correct alternative constant and varying the associative strength of the nonchosen alternative (e.g., high-high vs. highlow). The effect of associative strength was assessed by comparing conditions in which the alternatives were similar but the strength of their association with the focus word was changed (e.g., high-high vs. low-low).

In the present experiment, if the quality of necessary adjectives is the main factor influencing recall, the ArbArb group should recall fewer words than the Nec-Nec group. The performance of the Nec-Arb group, who are exposed to both types of adjectives, should be better than that of the Arb-Arb group, or at least should not be the poorest of the three groups. The cognitive-analysis view, however, would predict that the performance of the subjects in the Nec-Nec and the Arb-Arb conditions should be relatively similar, whereas the performance of the subjects in the Nec-Arb condition should be lower than that of the other two groups.

\section{Method}

Design and Materials. The design of this experiment consisted of the factorial combination of two variables: type of adjective (Nec-Nec, Arb-Arb, and Nec-Arb) and retention interval (immediate vs. 48-h delay). The stimulus materials consisted of 36 nouns; each noun had two necessary and two arbitrary adjectives. The nouns and one set of necessary and arbitrary adjectives were used in the pilot experiment reported in the introduction. Thus, normative data were available for one set of adjectives (Set 1). Another set of 36 necessary and 36 arbitrary adjectives (Set 2) was generated by using the same criteria used in the pilot experiment. In that experiment, three judges were presented with several necessary and arbitrary adjectives for each noun, and they determined the "best" adjective from this set. The adjectives chosen for the study were considered to be most appropriate by at least two of the three judges. Intralist similarity among adjectives was minimized; for instance, color names appeared only once in the list. The same procedure was followed for the selection of adjectives here. In addition, an attempt was made to equalize the difficulty of choosing between the two necessary adjectives and the two arbitrary adjectives. In other words, for a given noun, the two adjectives were chosen to be roughly equal in necessity or arbitrariness; that is, there would be no clear preference for one of the adjectives. In the Nec-Arb condition, the subjects received the necessary adjective from Set 1 and the arbitrary adjective from Set 2 .

All materials were presented in two-page booklets with 18 words per page. The nouns were typed in uppercase letters, and the adjectives in lowercase letters. The two adjectives always followed the noun.

Two random orders of nouns were used, and half of the subjects in each group received one of the two orders. Within each random order of nouns, each adjective appeared in a given position (left or right) for a random half of the subjects. Thus, there were four different versions of the materials.

In addition to the standard free-recall test, subjects in all groups were presented with single-cue recall and double-cue recall tests. In the single-cue recall test, the subjects were presented with Set 1 adjectives as recall cues. The subjects in the Nec-Arb condition were, therefore, cued with the necessary adjectives. In double-cue recall, both adjectives served as recall cues. Two random orders of cues were constructed, and each order was used equally often with one of the four versions of the acquisition list. Those subjects who received one order of single cues were given the other order of double cues.

In order to obtain an objective index of the difficulty of decision, an independent mixed-list rating study was conducted. The subjects were presented with the same set of materials used in the recall experiment, and they were required to circle the more necessary of the two adjectives. In addition, the subjects were instructed to rate the difficulty of their decision on a 5-point scale; a rating of 1 indicated a very easy decision, and a rating of 5 indicated a very difficult decision. Materials were presented in booklets. One-third of the 36 nouns were followed by two necessary adjectives, one-third by two arbitrary adjectives, and one-third by one necessary and one arbitrary adjective. The order of presentation of materials was counterbalanced across subjects so that each noun was modified by each pair of adjectives an equal number of times. There were two random orders of nouns.

Procedure. All learning was incidental, and the subjects were not informed of the forthcoming recall test. They were told that the experiment was part of a larger study of word meaning and that their task was to circle the more necessary of the two adjectives presented. The difference between necessary and arbitrary adjectives was defined clearly, and examples of each type of adjective were provided ("LETTUCE, leafy, rotten"; "FLAME, hot, dying"). Subjects in all conditions received the same set of instructions.

Beeps were recorded on a Wollensak 2556 tape recorder. A beep was presented every $15 \mathrm{sec}$ to indicate that the subjects should look at the next word. The subjects covered with a mask the words that they had not yet circled.

After completing the orienting tasks, the subjects in the immediate groups were tested for free recall. Single-cue and doublecue recall tests followed free recall. The subjects were allowed $5 \mathrm{~min}$ for each of the three recall tests. In the delay condition, after the completion of the orienting task, the subjects were told that Session 1 of the experiment was over and that in the nex 1 session they would participate in another meaning-related task In Session 2, these subjects were given the free-recall and single and double-cue recall tests in the same manner as the subjects in the immediate condition.

The normative study was conducted in introductory psychol ogy classrooms. The subjects rated the difficulty of their deci 
sion at their own pace. As indicated above, these subjects were presented mixed lists rather than the homogeneous lists used in the recall experiment.

Subjects. Ninety-six introductory psychology students from the State University of New York at Stony Brook served as the subjects in the experiment. The subjects were tested in small groups of four or fewer, and groups were assigned to the six treatment conditions by a randomized block schedule.

In the double-cue recall, 1 subject did not follow the instructions. The double-cue data are, therefore, included for 15 subjects per condition, a total of 90 subjects.

The subjects for the mixed-list rating study were 54 students from George Washington University. The subjects were divided into six groups, and each group received one version of the list (three different orders of counterbalancing by two random orders of nouns).

\section{Results and Discussion ${ }^{2}$}

Rating data. The mean ratings for difficulty of choosing the necessary adjectives were $2.63(\mathrm{SD}=.77), 2.06$ $(\mathrm{SD}=.62)$, and $1.72(\mathrm{SD}=.52)$ for the Arb-Arb, Nec$\mathrm{Nec}$, and Nec-Arb conditions, respectively. An analysis of variance revealed a significant effect of type of adjective $[\mathrm{F}(2,106)=61.88$. MSe $=25.54]$. Post hoc comparisons using Tukey tests indicated that the Nec-Arb condition differed significantly from both the Nec-Nec condition and the Arb-Arb condition. However, the ArbArb condition also differed significantly from the Nec$\mathrm{Nec}$ condition. One possible explanation for the latter finding is that subjects may have difficulty conceptualizing the arbitrary adjectives as necessary adjectives; this conceptualization is required to make a judgment about which adjective is more necessary.

Free-recall test. Figure 1 shows the mean number of correctly recalled words in the free-recall test. A $3 \times 2$ analysis of variance yielded a main effect of type of adjective $[F(2,90)=5.58$, MSe $=7.29]$ and a main effect

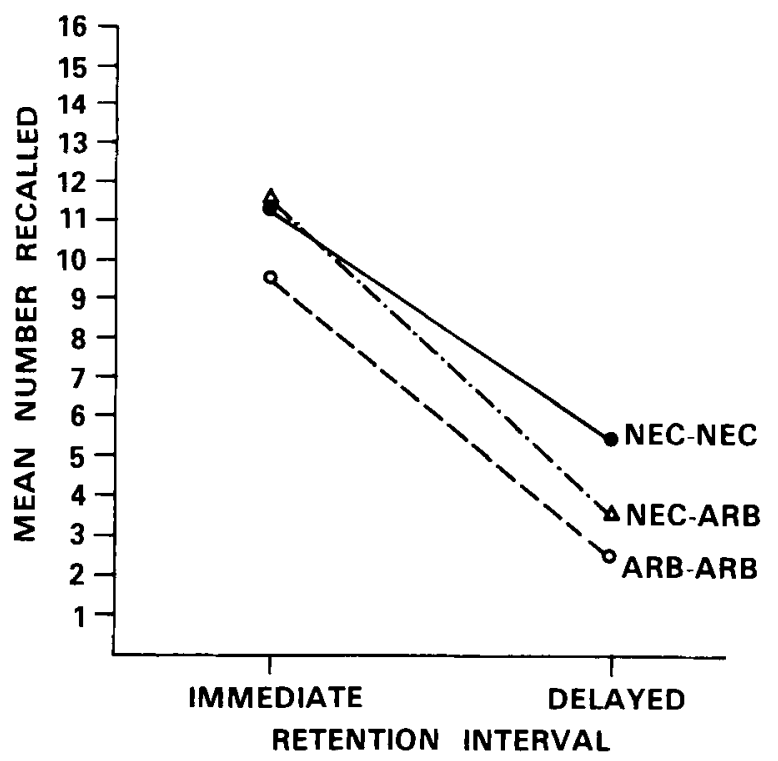

Figure 1. Mean number of correctly recalled words, free recall, Experiment 1. of retention interval $[F(1,90)=157.49]$. The interaction of type of adjective and retention interval was not significant $(F<1)$. Further analyses using NewmanKeuls tests indicated that the subjects in the Nec-Nec condition recalled a significantly greater number of words than the subjects in the Arb-Arb condition. Similarly, recall in the Nec-Arb group was superior to that in the Arb-Arb group. Recall in the Nec-Arb condition did not differ significantly from that in the Nec-Nec condition. A Tukey test, however, only showed a significant difference between the Nec-Nec and the Arb-Arb conditions.

These results indicate that it is the type of adjective, not the amount of cognitive analysis, that determines recall, and thereby support the core-meaning view. The Arb-Arb condition entailed extensive cognitive analysis but resulted in lower recall than the Nec-Nec condition. On the other hand, although the subjects in the NecArb condition had the simplest task of the three groups, their recall was not the lowest of the three groups. In fact, Newman-Keuls tests showed that the Nec-Arb condition resulted in significantly higher recall than the Arb-Arb condition, but it did not differ from the NecNec condition. It appears that an advantage accrues from even a single necessary adjective. In short, two clear patterns emerged from the data. First, there was no systematic relation between the amount of cognitive analysis as measured by the ratings and the amount of recall. Second, and perhaps more important, even with the more conservative Tukey test, two necessary adjectives (Nec-Nec) led to better recall than two arbitrary adjectives (Arb-Arb). This finding provides clear-cut support for the superiority of necessary over arbitrary adjectives.

It should be noted that, in contrast to Jacoby et al.'s (1979) studies, no effect of difficulty of decision (or cognitive analysis) was obtained in this experiment. Aside from differences in procedures (e.g., recall of nouns here and recall of the chosen alternative in Jacoby et al.'s studies), there is another explanation for this result. Jacoby et al. suggested that the preexperimental semantic relationship between items plays an important role in recall, whereas difficulty of decision is an important determinant of recognition. In the present experiments, necessary adjectives had a preexperimental semantic relationship with the nouns, and this relation. ship may have been emphasized by asking the subjects to choose the more necessary adjective from the two alternatives. Thus, the effect of semantic relationship could have overridden the effect of decision difficulty. Asking the subject to choose the more arbitrary adjective might show an effect of decision difficulty in addition to the effect of semantic relationship.

Cued-recall tests. The results of single- and double-cue recall tests were generally consistent with free recall. The mean numbers of correctly recalled words in immediate single- and double-cue tests were: $\mathrm{Nec}-\mathrm{Nec}=25.81$ $($ double $=34.13), \mathrm{Nec} \cdot \mathrm{Arb}=24.00($ double $=31.46)$, 
and Arb-Arb $=22.44$ (double $=30.33)$. The corresponding means for the delayed-recall tests were: 15.44 $($ double $=29.86), 11.31($ double $=20.86)$, and 9.94 $($ double $=21.90)$.

In both cued-recall tests, there was a main effect of adjective $[\mathrm{F}(2,90)=10.08, \mathrm{MSe}=16.22$, for single cue, and $F(2,84)=24.63$, MSe $=13.99$, for double cue $]$. Similarly, the main effect of retention interval was significant $[F(1,90)=207.92$, MSe $=16.22$, for single cue, and $F(1,84)=97.43$, MSe $=13.99$, for double cue $]$. Furthermore, in agreement with free-recall data, the interaction of type of adjective $\mathrm{x}$ retention interval was not significant in the single-cue test $(F<1)$; this interaction, however, was significant with the double-cue recall $[\mathrm{F}(2,84)=5.58, \mathrm{MSe}=13.99]$.

Additional post hoc comparisons using both NewmanKeuls and Tukey tests indicated that in both cuedrecall tests, the $\mathrm{Nec}-\mathrm{Nec}$ condition resulted in significantly higher recall than the Arb-Arb condition. However, the Nec-Arb condition was significantly different from the Nec-Nec condition but not from the Arb-Arb condition. Although it is not clear why the performance in the Nec-Arb condition was not entirely consistent in free and cued recall, the overall results were in greater agreement with the core-meaning than with the cognitive-analysis view. The latter view would predict lower performance in the Nec-Arb than in the Arb-Arb condition.

An alternative explanation for the double-cue recall results is that subjects are more likely to guess the correct response to two necessary adjectives than to either two arbitrary adjectives or to one necessary and one arbitrary adjective. To evaluate this "guessing" or freeassociation explanation, three independent groups of 12 subjects each were presented with Nec-Nec, Nec-Arb, or Arb-Arb adjectives and were asked to write down the first noun that came to mind. The mean proportions of correct nouns generated in the three groups were $30 \%$, $20 \%$, and $20 \%$, respectively. The generation data, therefore, suggest that the double-cue recall results might be subject to the guessing artifact. To minimize the effect of this guessing artifact on recall, the double-cue data were then rescored to include only those items that were equally likely to be generated from the adjectives in all three conditions. Ten of the 36 items met this criterion. All of these items were generated by 0 or by 1 subject of the 12 subjects in each generation group. Thus, not only were these items equal with respect to the probability of their being generated by different types of adjectives, but they also were unlikely to be produced as guesses to these adjectives.

The mean correct recall scores in the immediate condition for the subset of 10 items were 9.27, 8.53, and 7.86 for the Nec-Nec, Nec-Arb, and Arb-Arb conditions, respectively. The corresponding means for the delayed tests were $6.80,4.67$, and 4.80 . A $3 \times 2$ analysis of variance on these items showed that, in agreement with the previous analysis, the main effect of type of adjec- tive $[\mathrm{F}(2,84)=9.47, \mathrm{MSe}=2.65]$ and the main effect of retention interval $[F(1,84)=83.38]$ were significant. However, the interaction of type of adjective $\mathrm{x}$ retention interval was not significant $[F(2,84)=1.40]$. The latter finding may indicate that the previously unexplained interaction might have been in part due to the guessing artifact in the Nec-Nec condition.

Further analysis of the subset data using both $\mathrm{Tu}$ key and Newman-Keuls tests yielded results that were entirely consistent with the previous analyses on the total set of 36 items. Once again, the Nec-Nec condition resulted in significantly higher recall than the Arb-Arb condition, and the Nec-Arb condition was significantly different from the Nec-Nec condition but not from the Arb-Arb condition. Although it is difficult to generalize from a small set of items, the overall pattern of results suggests that simple free association cannot account for the double-cue recall data. Core adjectives are better retrieval cues for nouns than are peripheral adjectives, even when the preexperimental cue-to-target potency is equated for the two types of adjectives.

In summary, the results of this experiment are inconsistent with the cognitive-analysis explanation but support the core-meaning notion. The Nec-Nec group consistently showed higher recall than the Arb-Arb group. In addition, the Nec-Arb group had a simpler task than the Arb-Arb group but did not show lower performance than the Arb-Arb group.

\section{EXPERIMENT 2}

It can be argued that better recall with necessary adjectives is due to the specificity of these adjectives rather than to the activation of core properties by these adjectives. In this view, necessary adjectives may be more specific than arbitrary adjectives, with specificity referring to the size of the category of words/concepts that can be modified by an adjective. For example, "calibrated" may be a more specific adjective for "RULER" than is "plastic," since there is a relatively small category of items that are calibrated, at least smaller than the category of items that are plastic. Studies of semantic memory (Landauer \& Meyer, 1972) showed that retrieval time depends on category size-the larger the category, the longer the retrieval time. Frase and Kammann (1974) also showed that specific semantic-orienting tasks lead to better recall than do general tasks. It seems possible, therefore, that items from specific categories (necessary adjectives) might be more accessible than items from general categories (arbitrary adjectives). Experiment 2 was designed to separate the effect of relation to core from specificity of adjectives. In addition, this experiment would provide an independent replication of the beneficial effects of necessary adjectives with a different set of items.

Adjectives were varied on two dimensions, specificity (general vs. specific adjectives) and relation to the core (necessary vs. arbitrary adjectives). Examples of the four 
types of adjectives for a noun are: "straight RULER" (general necessary), "calibrated RULER" (specific necessary), "plastic RULER" (general arbitrary), and "metric RULER" (specific arbitrary). It was expected that regardless of the specificity of adjectives, items encoded with necessary adjectives would be remembered better than items encoded with arbitrary adjectives.

\section{Method}

The design of this experiment was a $2 \times 2 \times 2$ independent groups factorial, with type of adjective (necessary vs. arbitrary), specificity of adjective (general vs. specific), and retention interval (immediate vs. 48 -h delay) as the variables. A list of 36 nouns, composed of new nouns and a few old nouns (from Experiment 1), was used. Four adjectives were generated for each noun (general necessary, specific necessary, general arbitrary, and specific arbitrary). Intralist similarity among the adjectives was minimized. There were two random orders of 36 nouns, and half of the subjects in each group received one of the random orders. All materials were presented in two-page booklets, with 18 words per page. The nouns were typed in capital letters, and the adjectives were in lower-case letters.

The subject's task was to rate the adjectives listed for each noun. A rating of 1 indicated "definitely necessary," and a rating of 5 indicated "definitely arbitrary." The adjective always followed the noun, and the rating scale was drawn on top of each page. As in Experiment 1, necessary and arbitrary adjectives were clearly defined, and examples of each type of adjective were provided. After rating the adjectives, the subjects were presented with a surprise free-recall test either immediately or $48 \mathrm{~h}$ later. All other aspects of the procedure were identical to those in Experiment 1.

The ratings obtained from the subjects during the incidental task were used to check on the experimenter's intuition about the necessary and the arbitrary adjectives. In addition, at the end of the second session, the subjects were asked to rate the specificity of the adjectives. A rating of 1 indicated that the adjective was "definitely specific," and a rating of 5 indicated that the adjective was "definitely general." The same list of 36 nouns was given to all the subjects, but one-fourth of the nouns were paired with each type of adjective. Thus, each subject had been exposed to one-fourth of the adjectives before. The lists were counterbalanced so that, across subjects, each type of adjective occurred with each noun an equal number of times.

The subjects were 96 students from George Washington University, and they were paid $\$ 4$ for participation in two sessions. There were 12 subjects in each condition in the main task.

\section{Results and Discussion}

The mean ratings given by the subjects on the dimension of relation to the core (necessary vs. arbitrary) were: $2.40(\mathrm{SD}=.58)$ and $2.47(\mathrm{SD}=.47)$ for the necessary adjectives (specific and general, respectively), and $3.66(\mathrm{SD}=.53)$ and $4.00(\mathrm{SD}=.50)$ for the arbitrary adjectives (specific and general, respectively). These ratings were similar to the ratings obtained in the pilot experiment reported in the introduction. A one-way analysis of variance on the ratings revealed that there was a significant difference between the adjectival conditions $[\mathrm{F}(3,92)=65.48, \mathrm{MSe}=318.8]$. Further analysis showed that the necessary-adjective conditions (general and specific) had significantly lower ratings than the arbitrary-adjective conditions (general and specific) $[\mathrm{F}(1,92)=190.57, \mathrm{MSe}=318.8]$. The ratings on the specificity dimension were $2.69(\mathrm{SD}=.65)$ and 2.75 $(\mathrm{SD}=.73)$ for the specific adjectives (necessary and arbi- trary, respectively), and $3.71(\mathrm{SD}=.74)$ and $4.24(\mathrm{SD}=$ .77) for the general adjectives (necessary and arbitrary, respectively). Again, a one-way analysis of variance showed a significant difference in ratings among the adjectival conditions $[\mathrm{F}(3,285)=135.63, \mathrm{MSe}=32.86]$. A contrast of the ratings in the general-necessary and general-arbitrary conditions with those in the specificnecessary and specific-arbitrary conditions was significant $[\mathrm{F}(1,285)=372.84$, MSe $=32.86]$. Thus, the ratings verified the experimenter's intuition about necessary/arbitrary and specific/general adjectives.

Figure 2 shows the mean number of correctly recalled words in the free-recall test. There were main effects of retention interval $[\mathrm{F}(1,88)=96.87, \mathrm{MSe}=11.22]$ and of type of adjective $[F(1,88)=6.09]$. Thus, there was considerable forgetting over time, and encoding the words with necessary adjectives led to higher recall than did encoding the words with arbitrary adjectives. There was no significant effect of specificity of adjectives $[F(1,88)=1.88]$, and none of the interactions was significant $(F s<1)$. Necessary adjectives led to better recall regardless of whether they were general or specific.

It should be noted that there was no effect of specificity in this experiment. Although some experiments have indicated that specific terms may lead to better memory than do general terms (Landauer \& Meyer, 1972), most of these results have been obtained in a reaction time or a cued-recall situation. Recently, Gumenik (1979) suggested that the advantage of specific cues over general cues may be attributable to retrieval rather than to encoding. Furthermore, in the experiments demonstrating better free recall with specific encodings (Frase \& Kammann, 1974), specific categories were subsets of general categories so that activation of specific categories would automatically activate general categories (e.g., "water animals" vs. "animals"). Thus, the advantage of specific terms in these situations could be attributed to the greater number of features encoded with these terms. In the present experiment, specific adjectives were independent of general adjectives; that is, specific adjectives did not necessarily activate general properties of the nouns. The difference in the definition of specificity could account for the observed differences in recall.

The results of Experiment 2 provide a reliable replica-

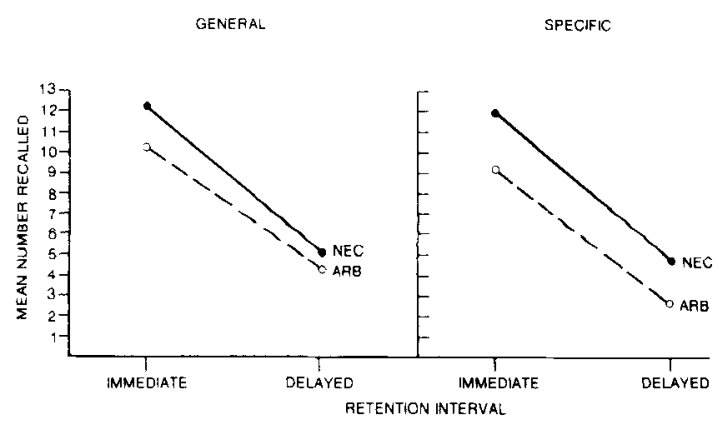

Figure 2. Mean number of recalled words, Experiment 2. 
tion of the beneficial effects of necessary adjectives with a different and more homogeneous list of items and indicate that the difference between necessary and arbitrary adjectives cannot be attributed to the specificity or the generality of these adjectives.

\section{GENERAL DISCUSSION}

The results consistently demonstrate that nouns en coded in the context of core adjectives lead to better re call than do nouns encoded in the context of peripheral adjectives. The beneficial effect of core adjectives seems to be independent of the amount of processing effort or specificity of these adjectives. In Experiment 1, the Nec$\mathrm{Nec}$ condition did not require a more difficult decision than the Arb-Arb condition but did result in higher free recall and cued recall than the Arb-Arb condition. The Nec-Arb condition required the least amount of cognitive analysis but did not lead to lower recall than the Arb-Arb condition. In Experiment 2, necessary adjectives, whether general or specific, led to better recall of nouns than did arbitrary adjectives. These findings clearly indicate that the specific quality of the semanticorienting task critically affects recall. In addition to providing support for the core-meaning notion, the results are also consistent with the conclusions of other recent investigators that, within the domain of semantic processing, the quality of elaboration is an important determinant of retention (Moscovitch \& Craik, 1976; Packman \& Battig, 1978; Stein \& Bransford, 1979;Stein, Morris, \& Bransford, 1978).

The distinction between core and peripheral aspects of meaning may seem inconsistent with the currently popular relativistic views of meaning. According to these views, the meaning of a word is contextually determined and there are no fixed aspects of meaning (Bransford et al., 1979). However, as mentioned in the introduction, the core aspects are not a priori logical or linguistic features; they are determined by the life history of an individual (Johnson et al., Note 1). Moreover, Jacoby and Craik (1979), while emphasizing the contextual determination of meaning, have pointed out that "it seems too extreme to argue that all aspects of the encoded trace are drastically modified by the context in which an event occurs (that is, that all aspects of the encoded description are relative to the specific context); presumably, some aspects are relatively invariant across contexts" (p. 5).

In addition, the results of several experiments by Bransford and his colleagues (Stein \& Bransford, 1979; Stein et al., 1978) have shown that "precise" statements that describe "nonarbitrary" relations between elements of a sentence (e.g., the hungry boy ate the hamburger) are recalled better than are "less precise" statements (e.g., the sleepy boy ate the hamburger). Although Bransford (1979) used the concept of precision in a relativistic sense, he also stated that the results of these ex- periments could be interpreted in terms of typicality. According to Bransford, "When statements express information that is relatively prototypic of previously acquired concepts, memory seems to be enhanced" (p. 176). In the experiments reported here, necessary adjectives provided "nonarbitrary" and typical descriptions of the target items.

Finally, it should be noted that researchers in the area of semantic memory have acknowledged the importance of context, but they have disagreed with the extremely relativistic views of meaning (Anderson \& Reder, 1979; Smith, 1978). For example, Smith argued that the results of experiments on semantic flexibility are not necessarily incompatible with the view that words are represented by a set of features that vary in salience, depending on the context.

Why does the activation of core aspects facilitate recall? According to Hasher, Griffin, and Johnson (1977), in a cued-recall or a paired-associate task, upon representation of the stimulus, core aspects are more likely to be reinstated than are peripheral aspects. Thus, activation of core aspects may constitute a "test appropriate encoding strategy" (see Lockhart, Craik, \& Jacoby, 1976) or, more generally, may reinstate the initial encoding. In addition, elaborators that utilize the core properties might be less susceptible to disruption than elaborators that involve the peripheral aspects (Hasher et al., 1977).

In a free-recall situation, in the absence of explicit cues, it is somewhat more difficult to explain why activation of core helps retention. However, several explanations may be suggested. First, the advantage of the necessary adjectives might be due to the characteristics of the units formed by the adjective-noun phrases (Horowitz \& Manelis, 1972). Arbitrary adjectives form a new unit with the noun, with few overlapping features between the unit and its parts. Necessary adjectives, on the other hand, form a well-integrated unit with many overlapping features. In the latter case, activation of any part (the adjective or the noun) will easily reinstate the other part. Or, as Horowitz and Manelis suggested, the greater the feature overlap between the adjective and the noun is, the greater the likelihood that activating the features will redintegrate the composite. Thus, not only are nouns more likely to reinstate the core elaborators (Hasher et al., 1977), but core elaborators that are spontaneously remembered are also more likely to reinstate the nouns.

Second, it is reasonable to assume that activation of core features simply results in a more "durable" encoding of the concept. According to this notion, when items are encoded with their typical features, they are more likely to be integrated with the preexisting semantic structures and they may be more accessible for later retrieval. The notion that utilization of preexisting knowledge structures at encoding increases the likelihood of recall has been proposed by several investigators. Solso (1974) suggested that subjects are more "hospitable" to 
reception of verbal stimuli that have "similar associative frameworks" to existing memory structures. The encoded trace is also more easily recoverable from the memory structures. Likewise, Horowitz and Manelis (1972) proposed that salient features "register more strongly." In addition, salient features are more likely to persist and may provide the functional cues that reinstate the encoded items (see Tulving, 1979).

In summary, it seems that a more detailed analysis of the nature of contextual elaborators and the relationship between these elaborators and preexisting semantic structures may provide a useful way of studying differ. ences within the semantic domain. In addition to the amount of semantic processing (Johnson-Laird et al., 1978), the type of semantic processing is an important determinant of recall. The effectiveness of various types of elaborators in immediate and delayed recall and the relative contribution of stimulus reinstatement factors and unit characteristic/trace durability factors require further examination.

\section{REFERENCE NOTE}

1. Johnson, M. K., Hasher, L., \& Hashtroudi, S. The core meaning of hypothesis and long-term retention. Unpublished manuscript, State University of New York at Stony Brook, 1978.

\section{REFERENCES}

Anderson, J. R., \& Reder, L. M. An elaborative processing explanation of depth of processing. In L. S. Cermak \& F. I. M. Craik (Eds.), Levels of processing human memory. Hillsdale, N.J: Erlbaum, 1979.

BAdDeley, A. D. The trouble with "levels": A reexamination of Craik and Lockhart's framework for memory research. Psychological Review, 1978, 85, 139-152.

Bransford, J. D. Human cognition: Learning, understanding and remembering. Belmont, Calif: Wadsworth, 1979.

Bransford, J. D., Franks, J. J., Morris, C. D., \& Stein, B. S. Some general constraints on learning and memory research. In L. S. Cermak \& F. I. M. Craik (Eds.), Levels of processing in human memory. Hillsdale, N.J: Erlbaum, 1979.

Craik, F. I. M., \& Lockhart, R. S. Levels of processing: A framework for memory research. Journal of Verbal Learning and Verbal Behavior, 1972, 11, 671-684.

Craik, F. I. M., \& Tulving, E. Depth of processing and the retention of words in episodic memory. Journal of Experimental Psychology: General, 1975, 104, 268-294.

Eysenck, M. W. Depth, elaboration and distinctiveness. In L. S. Cermak \& F. I. M. Craik (Eds.), Levels of processing in human memory. Hillsdale, N.J: Erlbaum, 1979.

Frase, L. T., \& Kammann, R. Effects of search criterion upon unanticipated free recall of categorically related words. Memory \& Cognition, 1974, 2, 181-184.

GuMENiK, W. E. The advantage of specific terms over general terms as cues for sentence recall: Instantiation or retrieval? Memory \& Cognition, 1979, 7, 240-244.

Hasher, L., Griffin, M., \& Johnson, M. K. More on interpretive factors in forgetting. Memory \& Cognition, 1977, 5, 41-45.

HAshe R, L., \& JohNSON, M. K. Interpretive factors in forgetting. Journal of Experimental Psychology: Human Learning and Memory, 1975, 1, 567-575.
Hashtroudi, S., \& Johnson, M. K. Transfer and forgetting: Interpretive shifts and stimulus reinstatement. Journal of Experimental Psychology: Human Learning and Memory, 1976, 2, 262-272.

Horowitz, L. M., \& Manelis, L. Toward a theory of redintegrative memory: Adjective-noun phrases. In G. H. Bower (Ed.), The psychology of learning and motivation. New York: Academic Press, 1972.

Hyde, T. S., \& Jenkins, J. J. Differential effect of incidental tasks on the organization of recall of a list of highly associated words. Journal of Experimental Psychology, 1969, 82, 474-481.

HYDE, T. S., \& Jenkins, J. J. Recall for words as a function of semantic, graphic and syntactic orienting tasks. Journal of Verbal Learning and Verbal Behavior, 1973, 12, 471-480.

JACOBy, L. L., \& CraIK, F. I. M. Effects of elaboration of processing at encoding and retrieval: Trace distinctiveness and recovery of initial context. In L. S. Cermak \& F. I. M. Craik (Eds.), Levels of processing in human memory. Hillsdale, N.J: Erlbaum, 1979.

JaCOBY, L. L., CraIK, F. I. M., \& BegG, I. Effects of decision difficulty on recognition and recall. Journal of Verbal Learning and Verbal Behavior, 1979, 18, 585-600.

JENKINS, J. J. Can we have a theory of meaningful memory? In $\mathbf{R}$. L. Solso (Ed.), Theories in cognitive psychology: The Loyola symposium. Potomac, Md: Erlbaum, 1974.

Johnson-Laind, P. N., \& Bethell-Fox, C. E. Memory for questions and amount of processing. Memory \& Cognition, $1978,6,496-501$.

Johnson-Laird, P. N., Gibbs, G., \& de Mowbray, J. Meaning, amount of processing, and memory for words. Memory \& Cognition, 1978, 6, 372-375.

KATZ, J. J. Analyticity and contradiction in natural language. In J. A. Fodor \& J. J. Katz (Eds.), The structure of language: Readings in the philosophy of language. Englewood Cliffs, N.J: Prentice-Hall, 1964.

KLEIN, K., \& SALTZ, E. Specifying the mechanisms in a level-ofprocessing approach to memory. Journal of Experimental Psychology: Human Learning and Memory, 1976, 2, 671-679.

Landauer, T. K., \& Meyer, D. E. Category size and semantic memory retrieval. Journal of Verbal Learning and Verbal Behavior, 1972, 11, 539-549.

Lockhart, R. S., Craik, F. I. M., \& Jacoby, L. Depth of processing, recognition and recall. In J. Brown (Ed.), Recall and recognition. London: Wiley, 1976.

Moscovitch, M., \& Craik, F. I. M. Depth of processing, retrieval cues, and uniqueness of encoding as factors in recall. Journal of Verbal Learning and Verbal Behavior, 1976, 15, 447-458.

Packman, J. L., \& Battig, W. F. Effects of different kinds of semantic processing on memory for words. Memory \& Cognition, 1978, 6, 502-508.

Putnam, H. The analytic and the synthetic. In H. Feigl \& G. Maxwell (Eds.), Minnesota studies in the philosophy of science (Vol. 3). Minneapolis: University of Minnesota Press, 1962.

Roediger, H. L., \& Thonpe, L. A. The role of recall time in producing hypermnesia. Memory \& Cognition, 1978, 6, 296-305.

Rosch, E. Cognitive representations of semantic categories. Journal of Experimental Psychology: General, 1975, 104, 192-233.

Smith, E. E. Theories of semantic memory. In W. K. Estes (Ed.), Handbook of learning and cognitive processes (Vol. 6). Hillsdale, N.J: Erlbaum, 1978.

Smith, E. E., Shoben, E. J., \& RIPs, L. J. Structure and process in semantic memory: A featural model for semantic decisions. Psychological Review, 1974, 81, 214-241.

Solso, R. L. Memory and the efficacy of cues or "Yes, I know!" vs. "Why didn't I think of that?" In R. L. Solso (Ed.), Theories in cognitive psychology: The Loyola symposium. Potomac, $\mathrm{Md}$ : Erlbaum, 1974.

Stein, B. S., \& Bransford, J. D. Constraints on effective 
elaboration: Effects of precision and subject generation. Journal of Verbal Learning and Verbal Behavior, 1979, 18, 769-777.

Stein, B. S., Morris, C. D., \& Bransford, J. D. Constraints on effective elaboration. Journal of Verbal Learning and Verbal Behavior, 1978, 17, 707-714.

Tulving, E. Relation between encoding specificity and levels of processing. In L. S. Cermak \& F. I. M. Craik (Eds.), Levels of processing in human memory. Hillsdale, N.J: Erlbaum, 1979.

\section{NOTES}

1. As discussed in the Introduction, necessary adjectives do not imply logical or linguistic necessity (Katz, 1964; Putnam, 1962). Necessary adjectives are simply more cross-situational descriptions of nouns than arbitrary adjectives.

2. The significance level for all statistical tests reported in this paper was set at $\mathrm{p}<.05$.

(Manuscript received July 6, 1982;

revision accepted for publication June 1,1983 .) 